\title{
"Tudo é questão de postura": o trabalho emocional realizado por agentes socioeducativos em centros de internação do Rio de Janeiro*
}

\author{
Juliana Vinuto**
}

\begin{abstract}
Resumo
Este artigo tem como objetivo discutir alguns aspectos generificados do trabalho dos agentes socioeducativos do estado do Rio de Janeiro em centros de internação para adolescentes em conflito com a lei. Ao descrever processos de patrulhamento de masculinidades, veremos como o trabalho emocional realizado por esses profissionais revela-se central para a construção de um modelo de atuação orientado por procedimentos de segurança em detrimento das atividades socioeducativas.
\end{abstract}

Palavras-chave: Agente Socioeducativo, Medida Socioeducativa de Internação, Patrulhamento de Gênero, Trabalho Emocional, Punição.

\footnotetext{
* Recebido em 03 de novembro de 2019, aceito 13 de agosto de 2020. Este texto apresenta parte dos resultados da pesquisa de doutorado já finalizada, realizada no Programa de Pós-Graduação em Sociologia e Antropologia da Universidade Federal do Rio de Janeiro. O presente trabalho foi realizado com o apoio CAPES por meio de bolsa de pesquisa de doutorado.

**Pesquisadora de Pós-doutorado pelo Programa de Pós-Graduação em Antropologia da Universidade Federal Fluminense (UFF), Niterói, RJ, Brasil. j.vinuto@gmail.com / https://orcid.org/0000-0002-6035-4463
} 
"Its All a Question of Posture": Emotional Work Conducted by Socio-Educational Agents in Youth Detention Centers of Rio de Janeiro

\begin{abstract}
This article discusses some gendered aspects of the work of socio-educational officers in adolescent detention centers in Rio de Janeiro that conflict with the law. By describing processes of patrolling masculinities, the study reveals how emotional work performed by these professionals is central to the construction of an operating model guided by security procedures to the detriment of socio-educational activities.
\end{abstract}

Keywords: Juvenile Detention Agent, Socio-Educational Measure of detention, Patrolling Gender, Emotional Work, Punishment. 


\title{
Considerações iniciais
}

\begin{abstract}
Esse é meu conflito, né, porque você acaba se envolvendo emocionalmente em algumas situações que você não está ali pra isso. Você pode fazer de forma humanizada e não se envolver emocionalmente (Agente socioeducativa feminina, centro de internação feminino, julho de 2016).
\end{abstract}

Hostil ou acolhedor, conservador ou criativo, prestigiado ou precário, são muitos os ambientes de trabalho em que os profissionais se envolvem emocionalmente, mesmo quando concordam que o melhor é não o fazer. Cobradores de impostos ou aeromoças (Hochschild, 2003), cuidadoras (Araujo, 2018), profissionais de telemarketing (Vilela; Assunção, 2007), enfermeiras (Vilela, 2013), dentre tantas outras profissões, alcançam seus objetivos a partir de relações com outras pessoas, das quais devem cuidar, convencer, informar, etc. São funções cujos profissionais não podem simplesmente reagir espontaneamente quando sentem raiva ou tristeza, pois isso pode causar prejuízos tanto para a organização na qual trabalham quanto para si mesmos, ou ainda para a população atendida. Sobre o imperativo de controle das emoções no trabalho policial, Ergon Bittner comenta:

O caso é simplesmente o seguinte: em uma ocupação que é direcionada principalmente para lidar com coisas que incitam sentimentos de ódio, indignação, menosprezo e medo na maior parte das pessoas, é duplamente importante manter tais sentimentos sob controle. Um policial que age apenas como qualquer pessoa agiria, perde naturalmente o direito de praticar uma ocupação especializada de qualquer espécie, sem falar em uma profissão (2017:187).

A fala da agente socioeducativa citada na abertura desta seção indica semelhanças com o argumento de Bittner sobre a organização policial. Porém, há uma diferença relevante: Bittner destaca a necessidade de manter sentimentos negativos sob controle, isto é, os sentimentos podem emergir, mas não devem influenciar a ação dos policiais. Já a agente socioeducativa entrevistada sugere a necessidade de não se envolver emocionalmente com o adolescente internado, ou seja, ela afirma a existência de emoções que não deveriam ser sentidas. Não se trata simplesmente de controlar emoções, mas de sentir emoções específicas, aquelas adequadas ao ambiente de trabalho. Ocorre aqui o que Arlie Hochschild (2003) chama de trabalho emocional.

O objetivo deste artigo é pensar como a demanda por trabalho emocional é parte relevante do cotidiano experienciado pelos agentes socioeducativos do Degase (Departamento Geral de Ações Socioeducativas), instituição responsável pela execução das medidas de semiliberdade e internação ${ }^{1}$ no estado do Rio de Janeiro. Nesse caso, importa pensar como o trabalho emocional afeta as representações construídas por esses profissionais sobre seu próprio trabalho, o que afeta a relação com o adolescente internado, rotulado pelo sistema de justiça juvenil como "em conflito com a lei".

Como dito em outro trabalho (Vinuto, 2020) os agentes socioeducativos são o coração da medida socioeducativa de internação, pois da mesma forma como esse órgão é responsável pelo fluxo de sangue por todo o corpo humano, esse é o profissional responsável pelos fluxos de atividade em um centro de internação. Isso ocorre porque os agentes socioeducativos são os profissionais que interagem com mais frequência com o adolescente internado, acompanhando-os em todas as suas atividades, dia e noite, seja dentro ou fora da unidade. Enquanto os demais profissionais de um centro de internação - como professores, assistentes sociais, psicólogos, pedagogos, etc. - interagem com o adolescente, sobretudo em momentos previamente agendados, são os agentes socioeducativos os responsáveis por levar os segundos até os primeiros.

\footnotetext{
1 As medidas socioeducativas são as sanções previstas no art. 112 do Estatuto da Criança e do Adolescente (ECA), destinadas a adolescentes com idade entre 12 e 17 anos incompletos que cometam atos infracionais. Existem as seguintes medidas socioeducativas: advertência, obrigação de reparar o dano, prestação de serviços à comunidade, liberdade assistida (medidas socioeducativas em meio aberto), semiliberdade (restritiva de liberdade) e internação (privativa de liberdade, considerada a mais grave)
} 
Como argumentarei neste artigo, os agentes socioeducativos relatam a existência de uma demanda latente que pode ser sintetizada na expressão ter postura com relação ao adolescente internado. Quando questionados sobre o que significava ter postura, foi perceptível a dificuldade dos agentes socioeducativos em explicar essa demanda, mas os elementos mobilizados indicavam a interdição de qualquer demonstração de empatia e a necessidade de demonstrar bravura $e$ agressividade. Tal contexto fortalece a desqualificação e/ou desconfiança dos agentes socioeducativos que não tem postura, isso é, aqueles profissionais vistos como mais alinhados à socioeducação, tidos muitas vezes como inocentes ou covardes, já que não conseguiriam colocar o adolescente em seu devido lugar ${ }^{2}$.

Como veremos, o imperativo da postura revela a exigência de um trabalho emocional fortemente atrelado às características de uma masculinidade hegemônica, ligada à demonstração de coragem e agressividade, que é cotidianamente construída nos centros de internação do Degase. Nesse sentido, pensar na multiplicidade e nas hierarquias entre diferentes modelos de masculinidade permite perceber modelos ideais de ser homem, sendo uns mais prestigiados do que outros, revelando modos hegemônicos de dever ser masculino. Tal masculinidade modelar de um dado grupo raramente é alcançado em sua plenitude, o que não impede que grande parte dos homens tente atingi-lo (Connel, 1995; Connel; Messerchmdt, 2003).Assim, se a princípio os homens desfrutam coletivamente de privilégios com relação às mulheres, por outro, estes homens não usufruem igualmente dessas vantagens, sendo importante considerar assimetrias de classe, raça, etnia, orientação sexual, dentre outros marcadores sociais da diferença e da desigualdade (hooks, 2004; Vigoya, 2018).

A demanda por ter postura opera como forma de desqualificação de tudo que é tido como feminino, o que ocorre inclusive nas tentativas de atuação alinhadas à socioeducação ${ }^{3}$, tidas como desarrazoadas em um contexto no qual a prioridade por disciplina, ordem e controle é vista como óbvia. Apesar do imperativo da postura parecer objetiva e não generificada, trata-se de uma demanda atravessada por estereótipos de gênero que permitem a segregação dos profissionais que desejam fazer socioeducação, sejam eles homens ou mulheres.

\section{Algumas discussões metodológicas}

Este artigo baseia-se em pesquisa de doutorado já concluída, realizada entre os anos de 2015 e 2019. A pesquisa de campo teve caráter etnográfico e trabalhou principalmente com os seguintes materiais: entrevistas semiestruturadas realizadas com 20 agentes socioeducativos de dois centros de internação diferentes, um feminino e outro masculino; conversas informais com agentes socioeducativos, dentro e fora das unidades; análise de material bibliográfico e institucional produzido pelo/sobre o Degase, de material disponibilizado em sites e redes sociais do Degase e do Sind-Degase (sindicato dos servidores do Degase) e de material jornalístico sobre o Degase; acesso a diários de campo compartilhados no âmbito do Projeto Parcerias ${ }^{4}$; participação em eventos $e$

\footnotetext{
2 Desse modo, trata-se de uma "postura" diferente da discutida por Robson Rodrigues da Silva (2009) em sua pesquisa sobre a iniciação e socialização entre futuros policiais militares durante os anos que passam na Academia de Polícia Militar D. João VI. Silva, ele mesmo um policial militar, discorre sobre a postura corporal exigida desses aspirantes a policial, que não poderiam demonstrar relaxamento por estar em desacordo com o ethos militar. Segundo Silva: "Creio que esse prisma possa nos oferecer uma nova possibilidade de entendermos melhor o fazer prático policial militar, por essa sua alternância postural característica, uma vez que o mimetismo corporal adquirido tradicionalmente com a ajuda do ritual na formação militar desaparece do corpo do policial militar na medida em que este vai do quartel à rua, e vice-versa (Silva, 2009:28).

${ }^{3}$ Há inúmeras obras sobre socioeducação (Abdalla; Veloso; Vargens, 2016) que propõem definições para o termo. Entre os agentes socioeducativos ocorre usualmente uma polarização entre os termos "segurança" e "socioeducação", isto é, um âmbito de punição e controle, muitas vezes até agressividade, e outro de aconselhamento, proteção e por vezes até afeto. Uma dimensão central para entender essa polarização é a discussão sobre direitos dos adolescentes internados: enquanto os profissionais que se definem como alinhados aos preceitos socioeducativos se posicionam a favor da garantia de tais direitos, aqueles que afirmam priorizar procedimentos de segurança costumam afirmar que os adolescentes não merecem tantos direitos, e por isso usualmente se posicionam a favor das propostas de redução da maioridade penal.

4 Trata-se de um projeto de extensão universitária coordenado pela Prof ${ }^{a}$ Hebe Signorini Gonçalves (Instituto de Psicologia da UFRJ), no qual estudantes realizavam visitas a uma unidade do Degase e participavam de reuniões semanais de supervisão para debater diários de campo previamente compartilhados.
} 
cursos oferecidos pelo Degase aos seus profissionais; participação em eventos organizados pelo Poder Judiciário e pelo Poder Legislativo sobre o Degase.

Apesar da multiplicidade de materiais de pesquisa, a frente mais desafiadora certamente foram as entrevistas ${ }^{5}$. Apesar das autorizações institucionais, é relevante ressaltar que uma das principais características da minha relação com grande parte dos agentes socioeducativos, assim como ocorre em outras "profissões que podem intimidar" (Bittner, 2017), foi a desconfiança. Essa desconfiança também orienta fortemente a relação desses profissionais com os adolescentes internados, pois entendem que a qualquer momento eles podem entrar em conflitos ou fugir do centro de internação. A desconfiança também baliza a relação entre agentes socioeducativos $e$ outros profissionais do próprio DEGASE, baseada na falta de fechamento (Vinuto, 2020). Há, ainda, uma forte desconfiança em relação a qualquer indivíduo externo que adentre um centro de internação, seja para a realização de pesquisa, trabalho voluntário, orientação religiosa, monitoramento, atuação jurídica, dentre outros.

Essa suspeita constante inevitavelmente afetou minhas possibilidades de pesquisa. Parte da desconfiança ocorria em virtude do tom acusatório com o qual é julgado o trabalho dos agentes socioeducativos, usualmente amparado em definições estereotipadas. Isso fomenta uma crença fortemente difundida entre agentes socioeducativos de que pesquisadores, defensores de direitos humanos, jornalistas e outros membros externos ao Degase não conhecem a complexa rotina de trabalho de um centro de internação, $e$ apenas adentram a instituição para avaliar negativamente o trabalho realizado. Apesar de não representar a maioria dos agentes com quem interagi, foram os agentes abertamente contrários à minha presença e a tudo o que eu representava, os que mais me afetaram. Tanto que, após um período de trabalho, percebi que eu sempre pressupunha que o profissional com quem eu conversaria seria hostil ao convite para participar desta pesquisa.

$\mathrm{Na}$ maior parte das vezes fui acolhida pelos agentes socioeducativos com os quais conversei, $e$ isso teve efeitos no desenvolvimento da pesquisa de campo. Em certa medida, todo pesquisador depende de sua aceitação no campo, e as conversas com pessoas mais pacientes e disponíveis tendem a fornecer informações mais detalhadas e profícuas (Vargas, 2000). Posso dizer que o acesso limitado aos agentes abertamente contrários à presença de pessoas externas no ambiente socioeducativo restringiu as informações que obtive sobre esse grupo. Mas essa franca oposição também foi uma fonte relevante de informação, já que essa constante tensão revela a força desse grupo minoritário de agentes socioeducativos contrários ao saber que eles definiam pejorativamente como teórico.

Apesar dos limites que o contexto impôs, foi justamente esse ambiente que me permitiu olhar para os conflitos entre estes agentes socioeducativos que ressaltavam que minha presença atrapalhava sua rotina de trabalho e aqueles trabalhadores que disponibilizaram parte de seu tempo para responder às minhas questões. Entendo tais diferenças como reflexo de conflitos que são centrais para a dinâmica cotidiana que fomenta a segurança enquanto prioridade auto-evidente em um centro de internação.

Nas próximas páginas, discorrerei mais detalhadamente sobre as especificidades do trabalho realizado pelos agentes socioeducativos em centros de internação do estado do Rio de Janeiro. Em seguida, debaterei sobre a construção cotidiana de um modelo hegemônico de masculinidade em centros de internação. Por fim, analisarei a centralidade da postura enquanto característica do trabalho emocional colocado aos agentes socioeducativos, que tem como efeito o reforço de um imperativo securitário baseado na agressividade e na interdição da empatia com o adolescente internado.

\section{Os agentes socioeducativos do DEGASE}

Agente: Os adolescentes ficam testando os agentes novatos, para ver como você reage, qual é a sua postura, se você é firme ou não é firme. Tudo isso. Eles não têm o que fazer, então eles vão

\footnotetext{
${ }^{5}$ As entrevistas foram autorizadas após aprovação pelo Comitê de Ética e pela Escola de Gestão Socioeducativa do próprio Degase, que permitiu a minha entrada nas unidades e, a partir de então, pactuei com as respectivas direções de unidade os dias de minha atuação [http://novodegase.ri.gov.br/esgse/ - acesso em 11 ago. 2020].
} 
te testar o tempo todo, até eles saberem qual é a sua (...). Então a questão do homossexual aqui eu acho complicado.

Pesquisadora: Porque ele também iria ficar sendo testado?

Agente: Ele não vai conseguir se impor. E isso vai criar um problema.

Pesquisadora: Para quem?

Agente: Para todo mundo! Para todo mundo!

(Agente socioeducativo masculina, centro de internação masculino, junho de 2016).

É comum ouvir dos agentes socioeducativos que o trabalho desenvolvido em um centro de internação depende da confiança uns nos outros. Um dos inúmeros pontos que pode causar insegurança nesse contexto é a desconfiança de que um deles não seja capaz de administrar um conflito entre adolescentes, de modo que um pequeno problema possa ganhar grandes proporções. Tal inquietação fica explícita na conversa que abre esta seção, em que o agente socioeducativo entrevistado receia que um agente homossexual não seja capaz de se impor frente aos adolescentes.

É possível perceber algumas premissas no referido diálogo: existe uma demanda constante para se impor ao adolescente, que parte da adequação a expectativas de gênero $e$ a não adequação de um servidor a essa demanda pode causar problemas na jornada de trabalho dos demais profissionais. Como veremos, tal demanda é vista como autoevidente e baseia grande parte das justificativas em prol da prioridade por procedimentos de segurança em detrimento das atividades socioeducativas.

Tal prioridade não é nova. Muitas pesquisas já indicaram como as instituições brasileiras de controle social voltadas a adolescentes rotulados como criminosos demonstraram raras práticas pedagógicas, tendo por objetivo prioritariamente disciplina, repressão e ordem (Zamora, 2005; Rizzini; Pilotti, 2009; Alvarez, 1989). Nesse sentido, os profissionais que atualmente são nomeados como "agentes socioeducativos" sempre tiveram a função semelhante à de carcereiros, ou seja, manter a ordem e evitar fugas de adolescentes internados (Abreo, 2017). Entretanto, o Estatuto da Criança e do Adolescente (ECA), promulgado em 1990 e baseado na Doutrina da Proteção Integral das Nações Unidas para a Infância (Vinuto; Duprez, 2019), impõe a necessidade de se centralizar o caráter educativo e ressocializador das mesmas. Essa mudança normativa ainda não foi totalmente absorvida na rotina de trabalho do Degase, acarretando em desorientação e/ou insatisfação em muitos agentes socioeducativos, que veem o trabalho de segurança e de socioeducação como mutuamente excludentes ${ }^{6}$.

Tal situação de hibridez institucional (Vinuto; Franco, 2019) fomenta diversas disputas entre diferentes agentes socioeducativos sobre o que deveria ser seu próprio trabalho (Vinuto, 2020). Em um contexto de superlotação, precariedade, desvalorização profissional e uma rotina de trabalho desgastante, além de presença de facções criminosas (Neri, 2009; Hernandez, 2018), muitos agentes socioeducativos destacam a impossibilidade de um trabalho de cunho educativo. Por isso, muitos profissionais afirmam priorizar procedimentos de segurança em sua jornada de trabalho, como realizar revistas pessoais e fazer o adolescente permanecer com as mãos para trás e a cabeça baixa, evitando o diálogo. E mesmo aqueles profissionais que declaram se alinhar aos preceitos educativos ressaltam que se sentem exceções, pois entendem que são minoria na instituição.

Essa é a conjuntura que revela a centralidade da postura do agente socioeducativo nos procedimentos de segurança frente a adolescentes privados de liberdade. Como afirma a psicóloga do Degase, Camila Meireles, em sua dissertação de mestrado:

Da confirmação de que há uma exigência implícita para que tenham "postura", ou seja, que reproduzam uma masculinidade que não permite a demonstração de sensibilidade, de fragilidade ou de empatia, à reflexão sobre o quanto eles mesmos acabam desqualificando ou pressionando aqueles que se posicionam diferentemente em relação aos adolescentes ou que demonstram um maior adoecimento (Meireles, 2019:119).

\footnotetext{
${ }^{6}$ Essa insatisfação é tamanha que, em 2018, os agentes socioeducativos conseguiram, a partir da atuação de seu sindicato, pressionar o Degase e o governo estadual para que a função passasse a ser nomeada como agente de segurança socioeducativa. Muitos profissionais ressaltam os ganhos dessa mudança, a partir da oportunidade de uma aproximação política e simbólica com outras forças de segurança estaduais, como as polícias e o sistema penitenciário.
} 
Observa-se aqui a explicitação das relações entre ter postura e uma masculinidade modelar específica, baseada na interdição da empatia com o adolescente internado e na valorização da agressividade durante a jornada de trabalho. Tal contexto faz com que aqueles que não têm postura sejam vistos como inadequados para o trabalho realizado na instituição, a partir de uma ligação pejorativa com atributos tidos como femininos, como o diálogo e o afeto. Nesse sentido, a socioeducação é tida como feminilizante e, portanto, como prejudicial na construção de uma performance tida como masculina.

Essa desqualificação dos profissionais que não demonstram ter postura é elemento relevante para o patrulhamento de masculinidades (Kimmel, 1998; 2005) existente nos centros de internação do Degase. Como veremos, em um espaço que pode ser analisado como casa-dos-homens (WelzerLang, 2001) e, portanto, que demanda performances tidas como masculinas, a competição incessante é vista como incontornável para a manutenção de uma imagem de profissional confiável, competente e corajoso. Assim, tal patrulhamento de masculinidades é processo e produto da construção de um modelo hegemônico de masculinidade baseada na agressividade e na interdição da empatia com relação aos adolescentes.

\section{A construção de um modelo hegemônico de masculinidade nos centros de internação cariocas}

A figura masculina impõe força, eles [os adolescentes internados] acham que toda mulher é frágil. Se um homem der um grito eles vão se assustar, e se a gente der um grito vão dizer que é histérica. Mas aí é o que eu te falei, tudo é questão de postura (Agente socioeducativo feminina, centro de internação feminino, junho de 2016).

Vemos, acima, um trecho de entrevista na qual uma agente socioeducativa explica algumas dificuldades específicas enfrentadas por mulheres que trabalham em centros de internação. Percebe-se que uma dimensão relevante é a força e a agressividade, mas para a entrevistada, agir de maneira agressiva não tem o mesmo efeito para qualquer agente socioeducativo: homens agressivos são assustadores, enquanto mulheres agressivas serão consideradas histéricas. Tal colocação sugere que mulheres têm mais dificuldades em performar uma imagem de agente socioeducativo disciplinador, pois como consta no excerto, a figura masculina impõe força, ou seja, a imagem masculina basta para passar uma mensagem de autoridade baseada na coerção. Mas apesar disso, a cobrança por essa performance tida como masculina é colocada a todos os profissionais que atuam em um centro de internação, pois como a entrevistada mesmo atesta: tudo é questão de postura.

Helena Hirata nos ajuda a entender essa compreensão binária e biologizante compartilhada socialmente nos espaços laborais. Para a autora, o estudo das atividades de trabalho segundo o par masculinidade e feminilidade revela o poder dos estereótipos sexuados no trabalho, já que

a virilidade é associada ao trabalho pesado, penoso, sujo, insalubre, algumas vezes perigoso, trabalho que requer coragem e determinação, enquanto que a feminilidade é associada ao trabalho leve, fácil, limpo, que exige paciência e minúcia (Hirata, 1995:43).

Em um centro de internação, esse tipo de compreensão binária e biologizante fortalece a tese de que o trabalho de segurança é realizado de maneira mais eficiente por indivíduos lidos como masculinos, pois depende de uma postura disciplinar e controladora. Nessa direção, algumas agentes sentem-se pressionadas a performar comportamentos que consideram masculinos a fim de serem respeitadas, o que é comum em qualquer instituição que se oriente por premissas masculinizantes. Segundo Angela Davis (2009), nesses locais mulheres podem ser levadas a cometer os mesmos atos de violência esperados por homens e, portanto, não estão imunes à acusação de promoverem o machismo.

Aqui vemos que a performance dessa masculinidade opera de forma central para a impressão de que o trabalho de segurança está sendo realizado de maneira adequada. Concomitantemente, os interessados no trabalho de socioeducação passam a ser lidos como femininos, isto é, como naturalmente afetuosos, sentimentais e fraternos, ou ainda, como covardes. Nesse contexto, a performance de uma masculinidade específica é vista como razoável e necessária em um centro de 
internação, tanto para homens quanto para mulheres, sendo importante compreender as consequências para aqueles que não são competentes em realizá-la.

O número de agentes socioeducativos homens é maior do que o de mulheres nos centros de interação do Degase $e^{7}$ (Vinuto, 2020), mas a primazia masculina não é apenas quantitativa. Assim como em outras profissões ligadas a segurança, ordem e disciplina (Malochet, 2005; Souza, 2014; Tardin; Lage, 2015; Zucatto, 2018), a presença de mulheres é acompanhada de marginalização e desqualificação simbólica das representações ligadas ao feminino. Tal contexto fortalece a hegemonia dos estereótipos masculinizantes, o que permite a segregação das mulheres de postos tidos como perigosos, inclusive com a concordância de muitas dessas mulheres (Le Gendre, 2017).

$\mathrm{Na}$ unidade masculina em que a pesquisa de campo foi realizada, a grande maioria de agentes socioeducativos são homens, sendo os únicos a lidar diretamente com os adolescentes internados. As poucas agentes socioeducativas realizam tarefas sem interação com os adolescentes, ou mesmo burocráticas, como organizar o livro de ocorrências ou ajudar na revista vexatória das visitas $^{8}$. Já na unidade feminina, agentes socioeducativos homens e mulheres desenvolvem praticamente as mesmas funções ${ }^{9}$, apesar de na maioria das vezes a posição de chefe de plantão ser ocupada por homens. A presença masculina em um centro de internação feminino é considerada necessária por grande parte dos agentes socioeducativos: enquanto os agentes masculinos reforçam a importância de sua presença por conseguirem manter a disciplina de forma mais eficiente, parte das agentes femininas ressalta que se sente mais segura com o acompanhamento dos agentes. Apesar disso, há coletivos de defesa de direitos humanos que se opõem a esta prática, o que influenciou na produção do Projeto de Lei Estadual $n^{\circ}$ 2131/2016, que proíbe a presença de agentes socioeducativos homens nas unidades femininas do Degase $e^{10}$.

Além dessa divisão sexual do processo de trabalho, há também certa divisão performática do trabalho, na qual é possível observar hierarquias não apenas entre homens e mulheres, mas também entre os próprios homens. Aqui àqueles que não performam a masculinidade esperada de maneira explícita e redundante, seja por serem ou parecerem homossexuais, seja por almejarem realizar um trabalho socioeducativo, são associados ao âmbito feminino e, consequentemente, tidos como incompetentes para o trabalho de segurança realizado no Degase.

Tais pressupostos relacionados a papeis de gênero que justificam as divisões sexual $e$ performática do trabalho possibilitam pensar esse espaço de interações entre agentes enquanto "casa-dos-homens" (Welzer-Lang, 2001), isto é, "um lugar onde a homossociabilidade pode ser vivida e experimentada em grupos de pares" (Welzer-Lang, 2001:462). Tratam-se de espaços nos quais homens mais experientes ensinam os novatos as regras para tornarem-se homens, $e$ onde a ação social é constantemente mediada pela violência. Apesar do foco analítico de Daniel WelzerLang ser a adolescência, isto não nos impede de pensar as interações de agentes socioeducativos em centros de internação, já que se trata de um espaço de aprendizagem de regras no qual os mais antigos "ensinam as regras e o savoir-faire, o saber ser homem" (Welzer-Lang, 2001:463). Como o próprio autor afirma:

\footnotetext{
7 Ao contrário do que ocorre nas penitenciárias adultas, no único centro de internação feminino do estado do Rio de Janeiro há também a presença de agentes socioeducativos homens. Para uma análise comparativa sobre a privação de liberdade de meninas do sistema socioeducativo e mulheres do sistema penitenciário, ver D'Angelo (2017).

8 A visita vexatória, também nomeada como visita íntima, é reconhecida como um procedimento de segurança por parte dos profissionais que trabalham tanto em unidades de medida socioeducativa quanto no sistema penitenciário, ao mesmo tempo em que é considerada como uma prática abusiva por ativistas de direitos humanos. Tal procedimento determina que os familiares que visitem instituições de privação de liberdade tirem a roupa e mostrem os órgãos genitais, a fim de provar que não estão portando nenhum item proibido. Importante destacar que no centro de internação feminino, onde realizei a pesquisa de campo, não havia revista vexatória de visitantes, já que a revista geral ocorria nas adolescentes depois das visitas. Desde 2016, o DEGASE recebeu investimentos para a compra de scanners corporais para evitar a realização de revista vexatória, mas até o final da minha pesquisa de campo, ainda havia constantes reclamações de que esta ainda ocorria.

9 A grande diferença fica por conta da revista nos alojamentos, que segundo os profissionais entrevistados, sempre deve contar com a presença de uma agente socioeducativo feminina, para evitar acusações de assédio sexual. Sobre as características específicas do centro de internação feminino do DEGASE, ver Leones (2018).

${ }^{10}$ [http://aleriln1.aleri.ri.gov.br/scpro1519.nsf/e00a7c3c8652b69a83256cca00646ee5/b99a4e0b7a81ae4c8325803d006a9 Of7?OpenDocument - acesso em: 24 mar. 2019].
} 
Estaríamos enganados se limitássemos a análise da casa-dos-homens à socialização infantil ou juvenil. Mesmo adulto, casado, o homem, ao mesmo tempo que "assume" o lugar de provedor, de pai que dirige a família, de marido que sabe o que é bom e correto para a mulher $e$ as crianças, continua a frequentar peças da casa-dos-homens: os cafés, os clubes, até mesmo as vezes a prisão, onde é necessário sempre se distinguir dos fracos, das femeazinhas, dos "veados", ou seja, daqueles que podem ser considerados como não-homens (Welzer-Lang 2001:465).

Pensar um centro de internação enquanto casa-dos-homens nos permite aprofundar o conhecimento sobre o processo de socialização profissional que ocorre entre os agentes socioeducativos (Vinuto, 2020). Nesse caso, verifica-se como a socialização profissional não apenas ensina o profissional novato a se tornar agente socioeducativo, mas também a se tornar um homem capaz de realizar um trabalho de segurança. Como a socioeducação é vista enquanto um trabalho com características femininas, todos aqueles que se alinharem aos preceitos socioeducativos serão lidos como tal. É por isso que mesmo homens heterossexuais podem sofrer os efeitos colaterais da homofobia (Nascimento, 2011).

Nem todos os agentes socioeducativos que acessei construíram relatos baseados numa divisão hierárquica entre masculino e feminino, nem relacionavam masculinidade com eficiência no trabalho de segurança. Sobretudo aqueles que afirmavam ser chamados pejorativamente de pão doce ou mamãezada, isto é, aqueles que se liam e eram lidos como profissionais que priorizavam atividades socioeducativas, tentavam ressaltar o quanto o vínculo afetivo era de grande auxílio para a realização do trabalho de segurança. Esses agentes socioeducativos argumentavam que os profissionais mais implicados com os adolescentes conseguiriam manter a ordem com apenas uma conversa, um olhar reprovador ou com sua presença próxima. Para esse grupo, as fronteiras entre socioeducação e segurança e, portanto, entre feminino e masculino, são mais fluidas do que aquelas sugeridas nos relatos construídos pelos agentes linha dura, ou seja, os profissionais que se liam e eram lidos como aqueles que se engajavam em discursos e práticas de lei e ordem. Apesar da narrativa antagônica construída pelos pão doce/mamãezada, é evidente a existência de uma dimensão generificada nos centros de internação do Degase, onde a performance de uma masculinidade modelar é central, frente a homens e mulheres, de forma que a prioridade destinada à segurança faça sentido e seja considerada razoável.

Olhar para esta masculinidade modelar permite acessar o contínuo patrulhamento de masculinidades (Kimmel, 1998) entre diferentes perfis de agentes socioeducativos. Michael Kimmel explica que:

(...) a masculinidade exige a evitação e o repúdio de todos os comportamentos que estão, mesmo que remotamente, associados à feminilidade ("sem coisa de viado"); isso requer um patrulhamento incessante dos limites da pessoa, uma vigilância incessante das performances de uma pessoa para garantir que ela seja suficientemente masculina (Kimmel, 2005:143, grifo e tradução nossos) ${ }^{11}$.

Há, assim, um patrulhamento de comportamentos e discursos, de si mesmo e dos demais profissionais, o que torna a reprodução de estereótipos ligados à virilidade e agressividade algo desejável, o que é considerado fundamental para a obtenção e manutenção da imagem de profissional competente. Trata-se de uma vigilância ininterrupta, mesmo quando não percebida, na qual a aversão a tudo que é considerado feminino mostra-se fundamental na construção daquilo que é tido como masculino. Esse processo fortalece o modelo idealizado de "homem de verdade", mesmo quando causa sofrimento, ansiedade, frustração e reprovação na grande maioria dos homens, que nem sempre conseguem se adequar a esta norma de homem ideal.

Marcos Antônio do Nascimento (2011:54) destaca que o patrulhamento de masculinidades "busca regular as expressões de afeto, fomenta o silêncio de muitos deles [homens] em mostrarem-

\footnotetext{
11 "Masculinity requires the avoidance and repudiation of all behaviors that are even remotely associated with femininity ('no sissy stuff"); this requires a ceaseless patrolling of one's boundaries, an incessant surveillance of one's performances to ensure that one is sufficiently male".
} 
se com opiniões contrárias ao senso comum machista com medo do julgamento dos outros homens". Em um espaço atravessado por superlotação, precariedade e suspeição generalizada, como é o caso dos centros de internação do Degase, uma masculinidade agressiva é vista como prevenção de conflitos. O patrulhamento de masculinidades acaba por segregar diferentes perfis de agentes socioeducativos ao criar critérios rígidos para o estabelecimento de confiança entre estes: aqueles e aquelas que têm alguma empatia pelo adolescente internado são vistos como não confiáveis, já que não performam a masculinidade da maneira esperada. Dessa forma, agentes rotulados como mamãezada ou pão doce são recorrentemente vistos com desconfiança pelos linha dura. Da mesma forma, o agente linha dura é costumeiramente visto como mais corajoso e viril, o que o tornaria adequado para o trabalho de segurança, que é considerado o objetivo prioritário da medida socioeducativa de internação por grande parte dos profissionais do Degase.

Nesse sentido, há uma relação de mútua influência entre a prioridade destinada aos procedimentos de segurança, a prescindibilidade com que é vista a socioeducação $e$ as expectativas de gênero entre agentes socioeducativos. A prioridade destinada aos procedimentos de segurança no Degase constrói uma demanda latente pela performance de uma masculinidade agressiva, tida como disciplinadora e viril; ao mesmo tempo, tal performance agressiva é vista como prova incontestável de que a prioridade pela segurança é uma dimensão incontornável da medida socioeducativa de internação. Assim, o patrulhamento de masculinidades é também processo e produto da prioridade destinada aos procedimentos de segurança existente nos centros de internação do Degase.

A partir de agora gostaria de descrever uma dimensão central para a performance da masculinidade patrulhada pelos agentes socioeducativos em seu cotidiano de trabalho: a expressão regulada das emoções. Algumas emoções são vistas como inadequadas na relação estabelecida entre adolescente internado e agente socioeducativo, o que dificulta a criação de vínculos entre as partes e torna o trabalho de segurança mais fácil de ser realizado. Dessa forma, a demanda de regulação das emoções interdita as possibilidades de realização do trabalho socioeducativo, já que minimiza as possibilidades de diálogo entre as partes.

\title{
Trabalho emocional e construção de uma masculinidade hegemônica nos centros de internação do Rio de Janeiro
}

\begin{abstract}
Mas assim, tudo é questão de postura. Desde que se tenha postura acho que não faz diferença [ser um agente socioeducativo heterossexual ou homossexual]. Se tiver uma postura firme com eles, saber colocar o adolescente no lugar dele, na condição dele de socioeducando, aí eu acho que não difere se é homossexual ou heterossexual. Não vai fazer diferença nenhuma, é tudo uma questão de ter postura mesmo (Agente socioeducativo masculino, centro de internação masculino, março de 2016).
\end{abstract}

O trecho acima refere-se a uma explicação dada por um agente socioeducativo que afirma que a orientação sexual dos profissionais que atuam em um centro de internação não é um impeditivo para o exercício da função, desde que saibam colocar o adolescente no lugar dele. Assim, questões de gênero e sexualidade até podem ter alguma influência na atuação profissional, mas desde que se tenha postura é possível atuar da maneira tida como adequada nesse espaço, ou seja, ter uma postura firme com os adolescentes internados. Aqui gênero e sexualidade aparecem de maneira supostamente secundária, já que há uma demanda que se apresenta como nãogenerificada e objetiva: ter postura. Porém, como já argumentei, trata-se de uma demanda masculinizante que constrói a obviedade cotidiana com que é vista a prioridade por procedimentos de segurança em detrimento de atividades socioeducativas em um centro de internação. Se concordarmos com Didier Fassin, podemos pensar que centros de internação são "um mundo hiper-masculino em que ninguém fala de masculinidade ${ }^{12}$ " (Fassin, 2015:336, tradução nossa), e assim compreender como a construção de um contexto masculinizante não depende da

12 "un monde hyper-masculin dans lequel personne ne parle de masculinité". 
compreensão individual sobre expectativas de gênero, que muitas vezes são mobilizadas de maneira despercebida.

Nessa direção, a postura necessária para colocar o adolescente no lugar dele implica necessariamente a interdição da empatia, tida por muitos profissionais como perturbadora dos procedimentos de segurança, já que abre espaço para o diálogo e, em alguma medida, para a contestação. Assim, grande parte dos agentes socioeducativos não apenas finge não ter empatia pelo adolescente internado, mas de fato se sentem proibidos de estabelecer qualquer tipo de vínculo emocional com o mesmo. Trata-se do que Hochschild (1979) chama de trabalho emocional, no qual o ator não tenta parecer estar feliz ou triste, mas trabalha ativamente para que seus sentimentos se adequem ao que é esperado para a situação. A autora ressalta que o termo "manipular" ou "controlar" emoções é inadequado, já que sugere uma superficialidade que não se relaciona com os propósitos de sua análise, isto é, as demandas sociais pelo gerenciamento profundo das emoções.

Nessa perspectiva, as emoções deixam de ser vistas apenas como expressão espontânea, cujo estudo seria prerrogativa exclusiva da psicologia (Mauss, 1979). Isso ocorre porque há uma dimensão social importante tanto na forma pela qual interações e relações afetam o que sentimos quanto nas emoções tidas como adequadas para cada situação. A partir de Hochschild, observa-se que a forma como se prescreve emoções aos agentes socioeducativos se ampara em uma dimensão organizacional, já que muitos de seus servidores sentem que só devem demonstrar as emoções institucionalmente aprovadas. Com relação a essa demanda por emoções específicas no trabalho de agentes socioeducativos, Abreo (2017:96) destaca:

É apresentado ao sujeito o "modelo agente" a ser incorporado com uma das poucas formas de continuar trabalhando: agente viril, corajoso, frio, que negue ou racionalize os problemas institucionais, que imponha ordens e que não tenha medo. Um agente que não seja frágil e que não demonstre sentimentos e emoções. Falamos de uma "armadura agente", um soldado para a organização, que atende à demanda institucional pela lógica da coerção e passa a atuar como reprodutor desta.

Hochschild justifica o termo trabalho emocional porque se trata de uma ação que, em grande medida, é imposta pelas organizações a seus profissionais e pode assumir a característica de uma jornada de trabalho extra, dada a centralidade da supressão da distância entre o que se sente e o ideal do que se deveria sentir. A autora faz uma analogia com o trabalho doméstico, pois apesar de ambos serem invisibilizados e não serem considerados trabalho são cruciais para que as atividades legitimadas enquanto "trabalho de verdade" sejam realizadas ${ }^{13}$.

Pensando nos agentes socioeducativos, há um trabalho emocional que é apropriado pelo Degase: como a segurança é tida como trabalho prioritário, grande parte dos agentes socioeducativos gerencia suas emoções para sentir o que consideram ser o mais adequado nesse contexto. Aqui é exemplar o caso do agente linha dura, que atua sobre si mesmo para não sentir empatia e, assim, produz ativamente a centralidade dos procedimentos de segurança, ao mesmo tempo em que mantém a postura demandada em sua jornada de trabalho, muitas vezes subjetivando-a e se considerando naturalmente agressivo.

O trabalho emocional, além do gerenciamento sobre as manifestações das emoções, implica também o controle da intensidade das emoções sentidas. Se o agente linha dura acha-se interditado de sentir empatia pelo adolescente, o grau dessa interdição não deve ser excessiva a ponto de sentir raiva do mesmo, o que criaria desavenças pessoais e estimularia a insubordinação, por incitar a

\footnotetext{
${ }^{13}$ É a partir dessa dimensão coercitiva que Anna Bárbara Araújo substitui o termo "trabalho emocional" por "demandas morais e emocionais do trabalho" em sua pesquisa sobre cuidadoras de idosos. Segundo a autora: "Defendo que o termo demandas morais e emocionais do trabalho deixa mais claro o caráter simultâneo de imposição e de prescrição pelo qual as emoções e moralidades são organizadas e tornadas parte do trabalho. Isto é, falar em demandas implica lançar luz sobre os processos de produção, assimilação e consumo das mesmas. Ou seja, me permite discutir transversalmente: 1) como essas demandas se estruturam a partir das relações de gênero e das dinâmicas do mercado de trabalho, e mais especificamente, das empresas de cuidado; 2) como são incorporadas pelas cuidadoras e que tipo de agência elas têm sobre essas demandas e; 3) como se fazem sentir nas interações cotidianas com os idosos" (Araújo, 2019:5).
} 
agressividade do adolescente. Da mesma forma, a empatia sentida pelo agente mamãezada/pão doce não pode ultrapassar o grau em que este se sinta no controle da situação, já que a intimidade excessiva costuma ser vista como o primeiro passo para uma relação abusiva por parte do adolescente, o que seria prejudicial para o bom andamento de sua jornada de trabalho.

Somado a isso, há também um gerenciamento ativo a partir do que se entende como os momentos adequados para sentir determinadas afetividades, já que há um consenso de que emoções sentidas durante a jornada de trabalho não devem ser "levadas para casa". Isso significa que há um entendimento comum de que espaços diferentes exigem emoções distintas, e que as emoções mobilizadas dentro do Degase são eminentemente diversas daquelas esperadas nas interações fora do ambiente de trabalho. Foi comum a construção de relatos de profissionais que percebiam que a impaciência sentida com relação aos adolescentes internados era prejudicial nas interações com os próprios filhos, ou que a melancolia decorrente do conhecimento das experiências de vulnerabilidade vividas pelos adolescentes entristecia o agente socioeducativo mesmo em seus dias de folgas. Estes são exemplos do que é visto como algo que deve controlado.

Importante ressaltar que o trabalho emocional não se restringe ao gerenciamento das próprias emoções, já que otermo "trabalho emocional" só deve ser utilizado para pensar as funções nas quais, além do controle das próprias emoções, haja também uma demanda organizacional por manipular as emoções de outrem. No trecho a seguir Hochschild ressalta as características principais das funções que demandam "trabalho emocional":

Trabalhos desse tipo têm três características em comum. Primeiro, eles exigem contato face-aface ou voz-a-voz com o público. Segundo, eles exigem que o trabalhador produza um estado emocional em outra pessoa - gratidão ou medo, por exemplo. Terceiro, eles permitem que o empregador, por meio de treinamento e supervisão, exerça um grau de controle sobre as atividades emocionais dos funcionários (Hochschild, 2003:147, tradução nossa) ${ }^{14}$.

O trabalho de agentes socioeducativos pode ser pensado a partir desses três pontos. Primeiro e mais evidente, trata-se de um trabalho no qual a interação com adolescentes é ininterrupta. Os agentes socioeducativos também veem a necessidade de produzir um estado emocional nos adolescentes internados, mas dada a hibridez existente na profissão (Vinuto; Franco, 2019), constrói-se a necessidade de dois tipos de ação, que variam de acordo com a forma como estes profissionais veem seu próprio trabalho: o agente linha dura almeja produzir medo no adolescente internado, o que é visto como ferramenta cotidiana e preventiva de trabalho, enquanto que o agente mamãezada/pão doce tenta produzir arrependimento, a fim de que sua função socioeducativa faça algum sentido, diante da constante sensação de enxugar gelo. Por fim, como sugere o terceiro ponto elencado pela autora, o Degase fornece treinamento e supervisão para que seus objetivos manifestos e latentes sejam realizados.

Por outro lado, apesar do objetivo do trabalho emocional ser o de produzir emoções em terceiros, importa mais a tentativa do que o resultado, já que mesmo os "atos de gerenciamento fracassados ainda indicam que formulações ideais orientam o esforço ${ }^{15}$ " (Hochschild, 1979:561, tradução nossa). Isso é de suma importância para pensar a rotina de trabalho nos centros de internação, já que mesmo que o medo ou o arrependimento esperados não sejam sentidos pelos adolescentes, importa compreender que estes fazem parte do que é tido como desejável nas rotinas vivenciadas pelos agentes socioeducativos.

Todas as vezes que um ator tenta sentir ou evita uma emoção específica, está aplicando, mesmo sem perceber, o que Hochschild chama de regras de sentimentos. Quando um profissional percebe a obrigatoriedade de sentir determinadas emoções ou de interditar outras, acaba por

\footnotetext{
14 "Jobs of this type have three characteristics in common. First, they require face-to-face or voice-to-voice contact with the public. Second, they require the worker to produce an emotional state in another person-gratitude or fear, for example. Third, they allow the employer, through training and supervision, to exercise a degree of control over the emotional activities of employees".

15 "Note that "emotion work" refers to the effort-the act of trying- and not to the outcome, which may or may not be successful. Failed acts of management still indicate what ideal formulations guide the effort, and on that account are no less interesting than emotion management that works".
} 
compreender quais são as regras de sentimento do contexto em que está inserido. Outra forma de perceber as regras de sentimentos é verificar a inspeção e avaliação dos membros do grupo uns sobre os outros. Isso ocorre porque "As regras de sentimento são padrões usados na conversação emocional para determinar o que é adequado e inadequado na moeda do sentimento" (Hochschild, 2003:18, tradução nossa).

Hochschild ressalta que as regras de sentimento operam de maneira diversa frente a grupos dominantes e dominados, como afirma a seguir:

Dada essa relação entre o status e o tratamento do sentimento, conclui-se que as pessoas em categorias de baixo status - mulheres, pessoas de cor, crianças - carecem de um escudo de status contra o tratamento mais pobre de seus sentimentos. Este simples fato tem o poder de transformar completamente o conteúdo de um trabalho ${ }^{17}$ (2003:174, tradução nossa).

As diferentes emoções prescritas a grupos dominantes e dominados fazem com que, mesmo quando indivíduos cumprem a mesma função, eles não realizem exatamente o mesmo trabalho. Hochschild dá especial atenção às distintas regras de sentimento impostas a homens e mulheres, devido à suposição de que suas naturezas diferem essencialmente. Como já descrevi, no caso dos agentes socioeducativos, é comum que mesmo exercendo a mesma função, homens e mulheres façam diferentes trabalhos: os agentes assumem cargos de liderança ou funções mais disciplinadoras, enquanto se espera que as agentes desenvolvam atividades distantes dos adolescentes ou baseadas no diálogo, e não no embate. Além disso, Hochschild afirma que por deterem menos poder, mulheres sentem-se obrigadas a realizar um maior trabalho emocional, pois percebem mais claramente uma necessidade em ocasionar determinadas emoções nos outros e de suprimirem as suas próprias. Em alguma medida, essas demandas específicas de trabalho emocional não ocorrem apenas frente às agentes socioeducativas femininas, mas também em relação a qualquer agente mamãezada/pão doce.

Dessa forma, Hochschild observa que: "Tomados em conjunto, o trabalho emocional, as regras de sentimento $e$ as trocas interpessoais moldam nosso sistema emocional privado ${ }^{18 "}$ (2003:76, tradução nossa). A autora sugere que os trabalhadores homens em funções tidas como masculinas se sentem legitimados para demonstrar sua raiva e fazer ameaças, ao contrário do que ocorre com as mulheres nas mesmas condições. A partir dessa abordagem, pode-se compreender que os agentes socioeducativos linha dura expressam sua agressividade porque se sentem legitimados para isso, o que acaba esculpindo a maneira como este vê a si mesmo, como um profissional enérgico ou até agressivo. E assim, os agentes linha dura subjetivam tal demanda, a positivando.

Vemos como a demanda por ter postura, apesar de aparentemente neutra em termos de gênero, apresenta uma dimensão generificada que fortalece o patrulhamento em busca de uma masculinidade modelar, baseada na agressividade e na interdição da empatia, cujo trabalho emocional é central. Trata-se de regras não declaradas, de difícil definição, mas que apresentam uma normatividade masculinizante.

Verifica-se a centralidade do trabalho das emoções sobre a construção de uma masculinidade específica nos centros de internação do Degase, que é patrulhada cotidianamente. Como as regras de sentimento são generificadas, isso acarreta também na generificação da atuação dos agentes socioeducativos, já que, como nos lembra Maria da Gloria Bonelli (2004:357), trata-se de um "processo no qual as pessoas tomam como referência um padrão de sentimento ideal construído na interação social, e procuram manusear e administrar suas emoções profundas para adequá-las a essa expectativa quando não estão sentindo assim internamente". Em uma situação de patrulhamento de masculinidades, o trabalho emocional é ferramenta importante para a plena

\footnotetext{
16 "Feeling rules are standards used in emotional conversation to determine what is rightly owed and owing in the currency of feeling".

17 "Given this relation between status and the treatment of feeling, it follows that persons in low-status categories - women, people of color, children - lack a status shield against poorer treatment of their feelings. This simple fact has the power to utterly transform the content of a job".

18 "Taken together, emotion work, feeling rules, and interpersonal exchange make up our private emotional system".
} 
realização da masculinidade modelar de um centro de internação, no sentido de convencer os demais sobre sua própria competência em realizar um trabalho de segurança, que como já dito, é aquele tido como prioritário em um centro de internação.

\section{Considerações finais}

Isso é uma cadeia, vamos dizer assim, ninguém chama, mas é. E é um negócio meio machista. Se a gente fizesse socioeducação de verdade, acho que haveria mais mulher no Degase. Mas para o trabalho de segurança, não tem jeito, é necessário mais homem mesmo (Agente socioeducativo masculino, centro de internação masculino, junho de 2016).

Este artigo almejou discutir algumas dimensões generificadas implícitas na demanda por ter postura colocada por muitos agentes socioeducativos para definir o que seria um trabalho adequado em um centro de internação. Como vimos, apesar de aparentemente ser uma demanda não generificada, os elementos que os agentes socioeducativos indicam para explicar o que seria ter postura revelam características tidas como masculinas, como a interdição da empatia e a agressividade.

Não à toa, frases como a citada acima são comuns. Entretanto, a prescindibilidade com que são vistas as profissionais mulheres em um contexto de privação de liberdade atinge outros profissionais, aqueles associados ao âmbito feminino $e$, consequentemente, tidos como incompetentes para o trabalho de segurança realizado no Degase. Esse e o caso de homens que não performam a masculinidade modelar instituída contextualmente - seja por serem ou por parecerem homossexuais - e/ou dos profissionais que se alinham ao discurso socioeducativo.

Tal hierarquização intraprofissional decorre de processos de patrulhamento de masculinidades nos quais aqueles profissionais que não aparentam ter postura são tidos como menos competentes para o trabalho realizado nos centros de internação do estado do Rio de Janeiro. Para compreendermos as demandas generificadas não manifestas existentes na jornada de trabalho dos agentes socioeducativos, é necessário olhar para o trabalho emocional realizado por esses profissionais. Desse modo, apesar do ter postura ser aparentemente neutro em termos de gênero, é atravessado por expectativas que são a base do patrulhamento de uma masculinidade modelar. $\mathrm{E}$ para se adaptar a esse contexto, muitos agentes empreendem um trabalho emocional visto como incontornável para projetar a imagem de profissional competente, o que ocorre mesmo frente aqueles com menos ferramentas para performar tal masculinidade, como é o caso dos agentes mamãezada/pão doce.

Assim, vemos como a demanda por ter postura apresenta uma expectativa baseada na agressividade e na interdição da empatia. Tratam-se de regras não declaradas, mas que apresentam uma normatividade masculinizante que afeta os modos como a medida socioeducativa de internação é implementada cotidianamente.

\section{Referências bibliográficas}

ABDALLA, Janaína. Socioeducação e educação social. In: ABDALLA, Janaína; VELOSO, Bianca; VARGENS, Paula (org.). Dicionário do Sistema Socioeducativo do Estado do Rio de Janeiro. Rio de Janeiro, RJ, Novo DEGASE, 2016, pp.328-352 [https://drive.google.com/file/d/1eyANeIAaxgk1Mv40r1EfqIcOnbHW3Wv/view].

ABREO, Leandro. Entre capturas e resistências: situações de saúde e adoecimento no trabalho de agentes socioeducativos. Dissertação (Mestrado em em Psicologia), Universidade Federal do Rio de Janeiro, 2017.

ALVAREZ, Marcos C. A emergência do Código de Menores de 1927. Dissertação (Mestrado em Sociologia), Universidade de São Paulo, 1989.

ARAÚJO, Anna Bárbara. Gênero, profissionalização e autonomia: o agenciamento do trabalho de cuidadoras de idosos por empresas. Dissertação (Mestrado em Sociologia), Universidade Federal do Rio de Janeiro, 2015.

BITTNER, Egon. Aspectos do trabalho policial. São Paulo, SP, Edusp, 2017. 
BONELLI, Maria da Gloria. Arlie Russell Hochschild e a sociologia das emoções. cadernos pagu (22), Campinas-SP, Núcleo de Estudos de Gênero-Pagu/Unicamp, 2004, pp.357-372 [https://www.scielo.br/scielo.php?script=sci_arttext\&pid=S0104-83332004000100015].

BRASIL. Sistema Nacional de Atendimento Socioeducativo (SINASE), Lei $\mathrm{n}^{\circ} 12.594$, de 18 de janeiro de 2012.

BRASIL. Estatuto da Criança e do Adolescente (ECA), Lei nº 8.069, de 13 de julho de 1990.

CECCHETTO, Fátima R. Violências e estilos de masculinidades. Rio de Janeiro, Editora FGV, 2004.

CONNEL, Raewyn. Masculinities. California, University of California Press, 1995.

CONNEL, Raewyn; MESSERSCHMIDT, James W. Masculinidade hegemônica: repensando o conceito. Revista Estudos Feministas, v. 1, n. 21, Florianópolis, 2013, pp.241-282 [https://www.scielo.br/scielo.php?script=sci_arttext\&pid=S0104-026X2013000100014].

D'ANGELO, Luisa B. Entre "sujeita-mulher" e "mulher de bandido": produções de feminilidades em contexto de privação de liberdade. Dissertação (Mestrado em Psicologia), Universidade do Estado do Rio de Janeiro, 2017.

DAVIS, Angela. A democracia da abolição: Para além do império, das prisões e da tortura. Rio de Janeiro, Difel, 2009.

FASSIN, Didier. L'Ombre du monde: une anthropologie de la condition carcérale. Le Seuil, 2015.

HERNANDEZ, Jimena de G. O Adolescente dobrado: cartografia feminista de uma unidade masculina do Sistema Socioeducativo do Rio de Janeiro. Tese (Doutorado em Psicologia), Universidade Estadual do Rio de Janeiro, 2018.

HIRATA, Helena. Relações sociais de sexo e do trabalho: contribuição à discussão sobre o conceito de trabalho. Em Aberto, v. 15, n. 65, 2008, pp.39-49 [http://emaberto.inep.gov.br/ojs3/index.php/emaberto/article/view/2316].

HOCHSCHILD, Arlie. Emotion Work, Feeling Rules, and Social Structure. American Journal of Sociology, v. 85 , n. 3,1979 , p. 551-575.

HOCHSCHILD, Arlie. The managed heart: commercialization of human feeling. California, University of California Press, 2003.

hooks, bell. We real cool: Black men and masculinity. PsychologyPress, 2004.

LE GENDRE, Anne-Christine. Femmes surveillantes, hommes detenus. Paris,L'Harmattan, 2017.

LEONES, Ana Karolina A. "O difícil é segurar a cadeia": a experiência da socioeducação feminina no estado do Rio de Janeiro. Dissertação (Mestrado em Sociologia), Universidade Federal Fluminense, 2018.

KIMMEL, Michael. Masculinity as Homophobia: Fear, Shame, and Silence in the Construction of Gender Identity. In: KIMMEL, Michael (ed.). The Gender of Desire: Essays on Male Sexuality. Albany, State University of New York Press, 2005, pp.25-42.

KIMMEL, Michael. A produção simultânea de masculinidades hegemônicas e subalternas. Horizontes Antropológicos, Porto Alegre, ano 4, n. 9, 1998, pp.103-117 [https://www.scielo.br/pdf/ha/v4n9/01047183-ha-4-9-0103.pdf].

MALOCHET, Guillaume. Dans l'ombre des hommes : la féminisation du personnel de surveillance du prisons pour hommes. Sociétés contemporaines, n. 59-60, 2005, pp.199-220.

MAUSS, Marcel. A expressão obrigatória dos sentimentos. In: MAUSS, Marcel. Antropologia. São Paulo, Ática, 1979, pp.147-153.

MEIRELES, Camila de C. Entre a educação e a disciplina: sobre agentes socioeducativos do Estado do Rio de Janeiro. Dissertação (Mestrado em Sociologia), Pontifícia Universidade Católica do Rio de Janeiro, 2017.

NASCIMENTO, Marcos A. F. Improváveis Relações: produção de sentidos sobre o masculino no contexto de amizade entre homens homo e heterossexuais. Tese (Doutorado em Saúde Coletiva), Universidade do Estado do Rio de Janeiro, 2011. 
NERI, Natasha E. Tirando a cadeia dimenor: a experiência da internação e as narrativas de jovens em conflito com a lei no Rio de Janeiro. Dissertação (Mestrado em Sociologia), Universidade Federal do Rio de Janeiro, 2009.

RIZZINI, Irene; PILOTTI, Francisco. A Arte de Governar crianças: a história das políticas sociais, da legislação e da assistência à infância no Brasil. São Paulo, Cortez, 2009.

SILVA, Robson R. Entre a caserna e a rua: o dilema do "pato" - Uma análise antropológica da instituição policial militar a partir da Academia de Polícia Militar D. João VI. Dissertação (Mestrado em Antropologia), Universidade Federal Fluminense, 2009.

SOUZA, Marcos S. "Sou policial, mas sou mulher": gênero e representações sociais na polícia militar de São Paulo. Tese (Doutorado em Ciências Sociais), Universidade Estadual de Campinas, 2014.

TARDIN, Elaine B; LAGE, Lana L. A mulher militar brasileira no século XXI: Antigos paradigmas, novos desafios. Revista Ágora, n. 22, 2015, pp.70-82 [https://periodicos.ufes.br/agora/article/view/13609].

VARGAS, Joana. Crimes sexuais e sistema de justiça. São Paulo, IBCCrim, 2000.

VIGOYA, Mara Viveros. As cores da masculinidade: experiências interseccionais e práticas de poder na Nossa América. Rio de Janeiro, Papeis Selvagens, 2018.

VILELA, Lailah V. O; ASSUNÇÃO, Ávila. Trabalho emocional: o caso dos teleatendentes de uma central de atendimento. Cadernos de Psicologia Social do Trabalho, v. 10, n. 2, 2007, pp.81-93 [http://pepsic.bvsalud.org/scielo.php?script=sci_arttext\&pid=S1516-37172007000200007].

VILELA, José. O trabalho emocional no ato de cuidar em enfermagem: uma revisão do conceito. Revista de Ciências da Saúde, v. 5, 2013, pp.41-50.

VINUTO, Juliana. "O outro lado da moeda": o trabalho dos agentes socioeducativos do estado do Rio de Janeiro. Rio de Janeiro, Autografia, 2020.

VINUTO, Juliana; DUPREZ, Dominique. O duplo objetivo sancionatório-educativo no Brasil e na França: as diferentes configurações organizacionais direcionadas ao adolescente em conflito com a lei. Revista

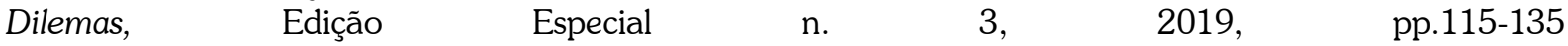
[https://revistas.ufrj.br/index.php/dilemas/article/view/23140].

VINUTO, Juliana; FRANCO, Túlio Maia. "Porque isso aqui, queira ou não, é uma cadeia": as instituições híbridas de interface com a prisão. Mediações-Revista de Ciências Sociais, v. 24, n. 2, 2019, pp.250-277 [http://www.uel.br/revistas/uel/index.php/mediacoes/article/view/35450/0].

WELZER-LANG, Daniel. A construção do masculino: dominação das mulheres e homofobia. Revista Estudos Feministas, v. 9, n. 2, 2001, pp.460-482 [https://www.scielo.br/scielo.php?pid=S0104026X2001000200008\&script=sci_abstract\&tlng=pt].

ZAMORA, Maria Helena. Para além das grades: elementos para a transformação do sistema socioeducativo. São Paulo, Edições Loyola, 2005.

ZUCATTO, Giovana E. "Não se nasce militar, torna-se militar":uma análise do processo de inserção feminina nas Forças Armadas Brasileiras. Dissertação (Mestrado em Sociologia), Universidade do Estado do Rio de Janeiro, 2018. 